Running-head: Reading in bilinguals

\title{
Cross-linguistic transfer in bilingual reading is item specific
}

Marie Lallier $^{*}$, Clara D. Martin ${ }^{1,3}$, Joana Acha $^{2,5}$, and Manuel Carreiras ${ }^{1,3,4}$

1. Basque Center on Cognition, Brain and Language, San Sebastián, Spain

2. Departamento Psicología básica, UPV/EHU, San Sebastián, Spain

3. Ikerbasque, Basque Foundation for Science, Bilbao, Spain

4. Departamento de Lengua Vasca y Comunicación, UPV/EHU, Bilbao, Spain

5. Biodonostia. Health Research Institute. San Sebastián, Spain

*Acknowledgements

This research was support by the Basque Government (BERC 2018-2021 program to BCBL, and PIBA_2018_1_0029 to C.D.M.), the H2020 European Research Council program (ERC-2018-COG-819093 to C.D.M.) and Spanish Ministry for Science and Innovation (PSI2017-82941-P and RED2018-102615-T to C.D.M., RTI2018-096242-BI00 to M.L., RYC-2015-17356 to M.L., and SEV-2015-0490 to the BCBL).

*Address for correspondence

Marie Lallier, m.lallier@bcbl.eu, Basque Center on Cognition Brain and Language, Paseo Mikeletegi 69, 20009 Donostia-San Sebastián, Spain

Keywords: bilingualism, reading, cross-linguistic transfer, grain size. 


\begin{abstract}
The grain size of orthographic representations prompted by a consistent orthography (like Spanish or Basque) increases if reading is simultaneously learned in another language with an inconsistent orthography (like French). Here, we aimed to identify item properties that trigger this grain-size accommodation in bilingual reading. Twentyfive French-Basque and 25 Spanish-Basque bilingual children attending Grade 3 read Basque words and pseudowords containing "complex" letter clusters mapping to one sound in French but several sounds in Basque or Spanish, and "simple" letter clusters mapping to the same sound structure in all three languages. Only French speaking children read "complex" Basque words faster than "simple" ones, suggesting that they accessed multi-letter "French" units to boost lexical processing. A negative complexity effect was found for pseudowords across groups. We discuss the existence of flexible cross-linguistic transfer in bilingual reading, proposing that the grain size of orthographic representations adjusts to item-specific characteristics during reading.
\end{abstract}




\section{Introduction}

It is estimated that half of the world population is bilingual (Grosjean, 2010). Among these individuals, some learn to read simultaneously in two orthographies. Although reading development is well documented in monolingual children, reading acquisition may follow distinct trajectories in bilinguals for various reasons. First, mastering and managing two linguistic systems on a daily basis changes the structure and connectivity of the brain (García-Pentón, Fernández, Iturria-Medina, Gillon-Dowens, \& Carreiras, 2014; Hull \& Vaid, 2007). Second, there is some evidence that bilinguals use resources acquired in one language to perform tasks in their other language, through crosslinguistic transfer. Classically, evidence for transfer from one language to another has been provided by correlation and regression analyses that measure the relationships between processes in the two languages (e.g., Genesee, Geva, Dressler, \& Kamil, 2006; Saiegh-Haddad \& Geva, 2010). However, this type of studies does not allow researchers to quantify the effects that this transfer has on the actual reading performance (speed or accuracy) of bilinguals. Lallier and Carreiras (2018) proposed that this issue could be addressed by comparing the performance of bilinguals with monolinguals or other groups of bilinguals. The present study examines two groups of bilinguals to shed light on the question of cross-linguistic transfer, and its consequences for bilingual reading performance, specifically regarding the reading grain size of orthographic representations.

The reading grain size is the size of the orthographic units used to access phonology from print when reading. Ziegler and Goswami (2005) proposed that the grain size is inversely proportional to the consistency of mappings between letters and sounds in the language learned. For example, French has an orthography where grapheme-to-phoneme conversions are complex and inconsistent such that the phoneme 
/e/ can be written in many ways, including "et", "er", "és", "ées", etc. French conversions may also be unpredictable (Schmalz, Marinus, Coltheart, \& Castles 2015). For instance, the grapheme "on" converts to /õ/ except in the irregular word "monsieur" where it converts to /œ/. In inconsistent orthographies, correct phonological decoding of sounds from letters largely depends on the relevant surrounding orthographic context. This context might correspond to just a few adjacent letters (e.g., et, aient, aint) or, in more extreme cases, to the whole word (e.g., "monsieur"). By contrast, conversion rules between graphemes and phonemes in consistent orthographies such as Spanish and Basque are simple and predictable such that (in most cases) reliance on single letters leads to accurate decoding. These cross-linguistic differences suggest that French readers must rely on larger grain sizes than Spanish readers when reading.

In line with this hypothesis, there is some evidence that orthographic consistency modulates the width of the visual attentional focus (or "the visual attentional grain size") on letter strings and its contribution to reading (Awadh, Phénix, Antzaka, Lallier, Carreiras \& Valdois, 2016; Rau, Moll, Snowling, \& Landerl, 2015). To refer to the size of the attentional focus during reading, the concept of visual attention span (VA span, hereafter) has been proposed. The VA span is defined as the number of visual elements that can be processed simultaneously in a multi-element array (Bosse, Tainturier, \& Valdois, 2007). With regards to reading, Bosse et al. (2007) demonstrated that the wider the VA span, the better the reading. In addition, the processing of all the letters of a word at once is thought to contribute to the build up and consolidation of whole word lexical representations (Chave, Ginestet \& Bosse, 2007), which is in line with the idea that VA span skills may be more important for lexical reading than sub-lexical phonological decoding. Accordingly, some dyslexic individuals who present reduced VA span skills do not show any phonological decoding difficulties (Peyrin et al., 2012; 
Valdois et al., 2003). Moreover, several studies showed that variations in VA span skills explained reading variance independently of the variance explained by phonological or verbal skills, (Bosse et al., 2007; Bosse \& Valdois, 2009; Lobier et al., 2013). Accordingly, VA span skills are measured with report tasks or 1-back tasks that include only consonants in the multi-letter sequences in order to minimize the reliance of phonological processes when performing the task. Overall, these studies suggest that a wide VA span reflects efficient processes that do not tax phonological resources, and is associated with the use of both a wider visual attentional focus and a larger grain size during reading.

Cross-linguistic observations show that a wide VA span benefits children learning to read in inconsistent orthographies, but is less critical for children learning to read in consistent orthographies (Lallier \& Carreiras, 2018 for a review). The underlying assumption is that the frequency of occurrence of multi-letter graphemes in a given orthography should determine (in part) the strategies used to distribute visual attentional resources over letter strings. This is consistent with data showing that statistical regularities in the visual environment (here, the presence of multi-letter graphemes in the orthography) affect visual attention selection (Theeuwes, 2018). Children who learn to read in an inconsistent orthography are more prone to widely distribute their visual attentional resources over letter strings (during both lexical and sub-lexical reading) because of the frequent occurrence of multi-letter sub-lexical chunks that map to a single sound. This fits well with the findings that developing readers rely more on lexical than sub-lexical reading if they learn to read in an inconsistent as compared to a consistent orthography (Ellis \& Hooper, 2001; Goswami, Gombert, \& de Barrera, 1998; Goswami, Ziegler, Dalton \& Schneider, 2001; Seymour, Aro, \& Erskine, 2003; Ziegler \& Goswami, 2005). This might be because "salient" 
multi-letter sub-lexical units in inconsistent orthographies, i.e., complex graphemes, speed up lexical access through the use of more efficient orthographic parsing strategies that help break lexical items down into intermediate units. From another branch of reading research, morphemes provide a good example of the "decomposition advantage" that results from salient sub-lexical multi-letter units since they have been shown to benefit reading by boosting lexical access (Burani, 2009; Burani et al., 2010; Hasenacker, Schröter \& Schroeder, 2017) and reduce demands on the attentional focus and VA span during reading (Antzaka, Acha, Carreiras, \& Lallier, 2018).

In the present study, we investigate whether and how cross-linguistic transfer affects the orthographic grain size in bilingual children. The results of previous studies suggest that bilinguals adapt and adjust their grain size depending on the orthographic consistency of the language to be read (Buetler, de León Rodríguez, Laganaro, Müri, Spierer, \& Annoni, 2014; de León Rodríguez et al., 2015; de León Rodríguez et al., 2016). To account for such effects, Lallier and Carreiras (2018) proposed the 'Grain Size Accommodation' hypothesis. One of the ideas developed by Lallier and Carreiras (2018) is that grain sizes that are beneficial for reading in one language may to some degree transfer to reading in the other language. Several studies have directly tested the "Grain Size Accomodation" hypothesis in different groups of bilinguals, and all of them suggest that the visual and orthographic grain size triggered by one orthography can be modulated by - or accommodated to - the grain size triggered by the other orthography in order to reach optimal processing strategies (Antzaka, Martin, Caffarra, Schlöffel, Carreiras \& Lallier, 2018; Lallier, Acha and Carreiras, 2016). In fact, such grain size adaptation may even provide some coping tools for reading difficulties. Lallier, Thierry, Barr, Carreiras, \& Tainturier (2018) demonstrated that Welsh $_{\text {consistent }}$-English ${ }_{\text {inconsistent }}$ bilinguals with dyslexia were less impaired than English monolingual individuals with 
dyslexia on English tasks for which the use of small grains was optimal (i.e., pseudoword reading and spelling). It was hypothesized that Welsh-English bilinguals with dyslexia could benefit from the use of small "Welsh-like" orthographic grains when performing these tasks in English.

However, one question still remains as to whether, when performing an orthographic task, bilinguals use an accommodated orthographic grain indifferently for all items or only for specific items. The idea that the grain size of orthographic representations is flexible and adapts to item orthographic characteristics during processing is not novel. Lexicality effects in reading already provide evidence that readers rely on larger orthographic grains when these are available in memory (i.e., for words) whereas they rely on smaller grains when larger grain strategies fail (e.g., for pseudowords, see Ans, Carbonnel \& Valdois, 1998).

In the present study, we attempt to identify what item characteristics might trigger the cross-linguistic transfer evidenced by grain size accommodation processes in bilingual reading. Our hypothesis is that grain size accommodation will only occur if these specific item characteristics are present. To tackle these questions, we study two very similar bilingual populations that offer a unique opportunity to explore crosslinguistic transfer and its consequences for reading performance: French-Basque and Spanish-Basque bilinguals. By comparing these two groups, we can quantify the differences in the reading grain size of Basque orthographic representations that result from cross-linguistic transfer from an inconsistent (French) versus a consistent (Spanish) orthography.

Basque, Spanish, and French share very similar alphabets as well as most orthotactic rules. In fact, almost all legal letter combinations in Basque are also legal in both French and Spanish. Therefore, it is not uncommon to find letter sequences in 
Basque that correspond to complex French graphemes: "orain" (/orain/, now in Basque) includes the grapheme "ain" that converts to the phoneme / $\tilde{\varepsilon} /$ in French but converts to the 3-phoneme sequence /ain/ in Spanish and Basque; "euria" (/euria/, rain in Basque) includes the grapheme "eu" that converts to the phoneme /œ/ in French, but is also a 2phoneme sequence /eu/ in Spanish. However, Basque words like "afari" (dinner) or "poliki" (gently) would be pronounced identically using a letter by letter decoding strategy given the grapheme-to-phoneme conversion rules in all three languages.

These observations show that it is important to consider the level of similarity between the grapheme-to-phoneme mapping rules in Basque and the bilingual's other language. Basque and Spanish share most mapping rules, whereas Basque differs from French, in particular, because complex Basque multi-letter graphemes can map to unique French vowel sounds. In fact, although all three orthographies share the same vowel letters (a, e, i, o and u), Basque and Spanish vocalic phonological repertoires only have five corresponding phonemes, whereas the French phonological repertoire comprises 14 vowel phonemes, many of which have to be accessed through multi-letter graphemes (e.g., ai, eu, in, ain, un, en, on, ou, etc.). This reflects an important phonological mismatch between Basque and French, whereas Basque and Spanish have highly similar phonological systems.

The present study

The main goal of the present study is to determine whether grain size accommodation processes are applied to all orthographic items indifferently or depend on the specific characteristics of these items. In order to address this question, we manipulated the presence of French complex vowel graphemes in two lists of Basque 
items (henceforth, "complex" versus "simple" reading lists). We expected responses to this manipulation to reveal that French-Basque bilinguals rely more heavily on large orthographic grains when reading complex compared to simple items even in the consistent Basque orthography. Based on previous studies on Basque bilingual readers (Antzaka et al., 2018; Lallier et al., 2016), we predicted that French-Basque bilinguals reading complex Basque lists would be more likely to recognize multi-letter graphemes "as wholes" since these are meaningful units in French reading. This would favor wider capture of visual attention for complex compared to simple words and, in turn, boost whole word processing and lexical access. In support of this hypothesis, Schmalz, Beyersmann, Cavalli, and Marinus (2016) demonstrated that French readers tend to rely more on lexical processes when reading complex as opposed to simple French words. These authors looked at frequency effects as a proxy to measure the use of lexical strategy, and found that words composed of complex multi-letter clusters elicited stronger frequency effects than simple words.

In the present study, French-Basque bilinguals who exhibit greater reliance on lexical processes were expected to show stronger lexical effects in the complex condition and possibly higher accuracy and faster reading times for complex than for simple Basque words. For the Spanish-Basque bilinguals, lexical effects and reading performance were expected to be similar for both complex and simple items.

Alternatively, we considered the possibility that a cross-linguistic mismatch in grapheme-to-phoneme conversions might hinder reading. If so, then French-Basque bilinguals should show a disadvantage when reading complex relative to simple words. Furthermore, this cost should be greater when reading non-lexical items which elicit more grapheme-to-phoneme decoding. 
To further test whether French-Basque bilinguals utilize a larger visual grain during complex item reading in Basque, we measured VA span skills in all our participants. First, we expected the VA span skills across letter strings would overall be wider and distribute more homogeneously in the French-Basque than the SpanishBasque bilingual group. This prediction relies on the account that learning to read in an inconsistent orthography encourages greater distribution of attention across letter strings (Antzaka et al., 2018; Lallier \& Carreiras, 2018; Lallier et al., 2016). Second, if large visual grain strategies are preferentially used by French-Basque bilinguals to process complex items, we predicted that VA span skills would be more strongly related to reading performance in the French-Basque than the Spanish-French group, and more so for complex than simple items.

\section{Material and Methods}

\subsection{Participants}

Twenty five French-Basque bilingual children (12 females; 107.5 months +/- 7.2) and 25 Spanish-Basque bilingual children (15 females; 106.6 months +/- 3.6) attending Grade 3 participated in the study. Signed consent from the legal tutor of the child was received prior to the study. The experiment was approved by the Ethics Review Board of the Seventh Framework Programme of the European Union as well as the Ethics Review Board of the BCBL and complied with the guidelines of the Helsinki Declaration. Children were recruited in the northern (French) and southern (Spanish) regions of the Basque country which feature a similar program of bilingual education in the primary education cycle. In ikastolas ("school" in Basque), most of the teaching is 
done in Basque, but from Grade 2 onwards, several hours of Spanish or French (2 to 4 hours per week) are added to the curriculum. Therefore, all children in the study had first learned to read in Basque. Information on language use and exposure was obtained from a questionnaire sent to the parents of all children involved in the study. On average, children had learned Basque and their other language between 0 and 2 years of age. Importantly, the two bilingual groups acquired their non-Basque language (i.e., French or Spanish) at similar ages (French-Basque bilinguals: $\mathrm{M}=1.6$ years, $\mathrm{SD}=2.5$; Spanish-Basque bilinguals: $\mathrm{M}=1.8$ years, $\mathrm{SD}=2.5$ ). A language use and habits questionnaire, created for the purpose of the present longitudinal project, was given to parents prior to the experiment. The questionnaire included a language use measure querying the averaged percentage of the child's use of a language in various situations, i.e., speaking, listening, writing, and reading. The question asked in the questionnaire was the following: "Indicate on average the percentage of time during which the child speaks/hears/writes in/reads in these languages - the sum of all percentages should add up to $100 \%$ : French [or Spanish, depending on the group], Basque, English, and others". The reliability of the language use indexes was assessed with a temporal test-retest consistency test since the same data had been collected one year before in the same children as part of a longitudinal project. The analyses indicated a high correlation of 0.81. The two bilingual groups differed in the use of their non-Basque language at the time of testing $(p<0.006)$ but not in their use of Basque $(p>0.05)$. Overall, FrenchBasque bilinguals used their non-Basque language more $(M=39.8, S D=15.0)$ than Spanish-Basque bilinguals $(\mathrm{M}=25.7, \mathrm{SD}=11.3)$. Since inter-individual variability in the use of the non-Basque language at the time of testing could influence the impact of cross-linguistic transfer on Basque reading performance, this measure was controlled for in subsequent analyses of the reading and reading-related tasks. 


\subsection{Task battery}

The tasks were administered across two or three sessions of approximately 30 minutes each (depending on the time the child needed to perform the task, and the duration of breaks). Children performed the tasks in their schools, following a schedule organized in consultation with teachers and directors. Participants were tested in a room where noise levels were minimal.

All children were administered a nonverbal IQ task to rule out the possibility that any group effect might result from differences in the general reasoning skills of the children rather than factors linked to the consistency of orthography. In addition, French-Basque bilinguals were administered a French reading task standardized in a monolingual French population. Since one of our main interests was complexity effects on Basque reading due to the influence of French, we wanted to ensure that after two years of reading instruction in French, the French-Basque bilinguals had developed sufficient French lexical orthographic skills to allow for possible cross-linguistic transfer. Finally, all children were administered the experimental reading task in Basque as well as a VA span task in order to test our specific hypotheses on the role of the distribution of visual attention in complexity effects in Basque.

The order of the administration of tasks was counterbalanced across participants. All the testing and instructions were administered in Basque by a fluent bilingual speaker of Basque and French or Basque and Spanish.

\subsubsection{Non-verbal IQ}


Children were given the matrices subtest of the WISC-IV (Wechsler, 2005) to obtain an index of their non-verbal reasoning skills. Based on previous report, the reliability of the Matrices WISC-IV subtest for the age range of interest is 0.89 (Wechsler, 2005). Scores obtained (for the 35 matrices administered) in an unlimited amount of time were recorded and analyzed. The task was ended if children made four consecutive errors or four errors within five consecutive trials.

\subsubsection{French standardized reading lists}

French-Basque bilinguals were administered three standardized reading lists from the French ODEDYS battery (Jacquier-Roux, Valdois, \& Zorman, 2002), which include 20 regular words, 20 irregular words, and 20 pseudowords. Items between lists are matched for letter and syllable lengths, grammatical class, and frequency. The 20 pseudowords are legal pseudowords without lexical neighbors. Participants were instructed to read each of the three lists aloud as quickly and accurately as possible. We recorded the total time taken to read each list with a chronometer and counted the number of errors made. Errors were recorded during the experiment.

\subsubsection{Basque reading lists: quantifying the "complexity" effect in Basque}

Children were presented with four lists of 40 items (2- to 4-syllables long): one was composed of complex Basque words, one of simple Basque words, one of complex Basque-like pseudowords, and one of simple Basque-like pseudowords (see the Appendix). Words were selected from the BaSp database (Duñabeitia, Casaponsa, Dimitropoulou, Martí, Larraza, \& Carreiras, in preparation). The complex and simple words were matched for frequency, number of syllables, number of letters, number of phonological neighbours, and age of acquisition (all ps $>0.05$ ). Complex and simple 
pseudowords were created by changing one or two letters in the complex and the simple Basque words (taken from the same database), all of which were matched for the aforementioned properties (all ps >0.05). Complex items included one or two multiletter clusters that could be mapped onto one unique vowel phoneme (i.e., ai, an, ain, au, en, ei, eu, er, in, oi, on, un) if they were read using French grapheme-to phoneme conversion rules ${ }^{1}$. The average French token frequency of the complex clusters used in our task was very high $(\mathrm{F}=10.975$ per million words), as computed with the Manulex_morpho database (Peereman, Sprenger-Charolles, \& Messaoud-Galusi, 2013). Simple items did not include any of these clusters, i.e., they would be pronounced similarly if read using French, Basque, or Spanish grapheme-to-phoneme conversion rules. Children were presented with the list of items on a sheet of paper and were instructed to read them aloud one by one as quickly and accurately as possible. The order of the lists was counterbalanced across participants. For each of the four lists, the number of errors made was collected. These errors were identified and written down during the experiment by a native Basque experimenter and included the erroneous pronunciation of items with respect to Basque grapheme-to-phoneme conversion rules, and items that were left out. If a child struggled to read an item for too long, they were encouraged to leave this item out and keep on reading. The total time taken to read the 40 items with was recorded by the experimenter with a chronometer. Note that wholelist reading speeds might seem a less reliable measure to capture reading speed variations than averaged reading times across items presented on a screen one by one. However, it has been shown to be a potentially good measure of reading speed

\footnotetext{
${ }^{1}$ A critical manipulation of our study was to insert French complex (inconsistent) multi-letter graphemes within Basque words in order to create our "complexity effect" in Basque. Hence, it was important for these French complex clusters to represent legal and frequent clusters in Basque. Letter units that correspond to French inconsistent consonantal graphemes are much less frequent in Basque (sometimes even illegal) than inconsistent vowel graphemes. In any case, had we manipulated the consistency of consonantal graphemes in our task, the predictions would have remained the same.
} 
influenced by list characteristics (Lallier et al. 2018; Wimmer \& Goswami, 1994; Zoubrinetzky, Bielle, \& Valdois, 2014). In addition, such procedures are more ecologically valid than presenting words one by one a computer screen, since they aim to "mimic" more continuous reading. This was one of our interests since we were testing young children.

An odd-even split was used to calculate split-half reliability of accuracy in the reading task. The correlations between all individuals's scores on odd and even trials were adjusted using the Spearman-Brown prophecy formula to approximate the reliability of the tests overall. The reliability measure obtained was 0.78 . As we collected the total reading time for each list of items, we could not use the odd-even split method to compute the reliability index for this measure. Thus, we performed correlation analyses between the individual total time measures obtained on the four reading lists. These values give us an index of the consistency of the measure collected across the four reading lists. All correlation coefficients were highly significant and were between 0.95 and $0.98(\mathrm{ps}<0.0001$; Bonferroni adjusted threshold $=0.008)$.

\subsubsection{Visual attention distribution over letter strings: Visual 1-back task}

The visual 1-back task is typically used to measure VA span skills (Lallier et al., 2016, Lallier, Carreiras, Tainturier, Savill \& Thierry, 2013). A list of 103 5-consonant strings was created using 13 consonants present in the Basque, French and Spanish alphabets (i.e., B, D, F, G, H, K, L, M, N, P, R, S and T). These consonant strings did not include grapheme clusters corresponding to either Basque, French or Spanish phonemes (e.g., $\mathrm{CH}, \mathrm{TS}$ ) and did not constitute word skeletons in any of the three languages (e.g., T M P N S, for "tympans" in French). Stimuli did not include the same letter twice. They were presented in black upper-case Arial font on a white screen by Presentation software 
installed on a PC computer. The space occupied by the items on the screen varied from $5.3^{\circ}$ to $5.55^{\circ}$ of visual angle at a distance of $70 \mathrm{~cm}$. The centre-to-centre distance between each adjacent letter was $1.2^{\circ}$ so that lateral masking effects were minimized. At the start of each trial, a central fixation point was displayed for $500 \mathrm{~ms}$ followed by a white screen of $100 \mathrm{~ms}$, then the 5-consonant string was displayed centered at fixation for $200 \mathrm{~ms}$. The consonant string was followed by a white screen of $100 \mathrm{~ms}$ and a single (target) letter appearing below or above (half of the trials) the median horizontal line. To reduce visual similarity to the strings, target letters were presented in red in a bolditalic font. Participants were instructed to press the "Alt Gr" key as fast as possible if the target letter was present in the consonant string and the "Alt" key when it was absent. The target disappeared immediately after the child's response, and a blank screen was presented until the experimenter pressed the left button of the mouse to initiate the next trial. The 103 trials were presented randomly, and included 65 target-present trials (the 13 consonants were presented 5 times as target, once at each position in the string) and 39 target-absent trials (the 13 consonants were presented 3 times as target). This combination of trials per conditions resulted in a probability of getting the right "YES" answer equal to .63 . However, the higher the probability of giving a specific type of answer (here the $63 \%$ chance of being accurate when responding "YES"), the more likely people are to underestimate the chance level. Therefore, the chance threshold was expected to be around 55\% accuracy (Lee \& Danileiko, 2014). The test trials were preceded by five practice trials. Response accuracy for target detection was recorded accounting for the position of the target in the string (hits and misses), as well as when the target was absent (correct rejections and false alarms). D-primes were then computed. Importantly, a high rate of target detection on this task (i.e. identification of a large number of consonants within the previously presented sequence) was previously 
shown to be associated with successful distribution of visual attention resources over a whole consonant string and with a larger VA span (Lallier et al., 2016, Lallier et al., 2013). An odd-even split was used to calculate split-half reliability of the accuracy of task. The correlations between all individuals' scores on odd and even trials were adjusted using the Spearman-Brown prophecy formula to approximate the reliability of the tests overall. The measure obtained was 0.75 .

\section{Results}

\subsection{Non-verbal IQ}

A independent t-test conducted on the scores obtained on the matrix subtests of the WISC battery with Group (French, Spanish) as the independent variable did not show any group effect (French-Basque bilinguals: $\mathrm{M}=15.21, \mathrm{SD}=3.03$; Spanish-Basque bilinguals: $\mathrm{M}=14.52, \mathrm{SD}=3.65 ; \mathrm{t}=0.65, \mathrm{p}>0.05$, Cohen's $d=0.20)$.

\subsection{French standardized reading lists}

Table 1 presents the performance of the French-Basque bilingual children on the three reading lists. As a group, the French speaking children performed well within the range of age-matched children on all accuracy and time measures: all z-scores were between $0.58(\mathrm{p}=0.28)$ and $-0.07(\mathrm{p}=0.47)$, showing that the French reading skills of the FrenchBasque bilingual group did not differ from those of French monolingual children of the same age.

---- Insert Table 1. about here ----- 


\subsection{Basque reading lists (Table 2)}

The ANCOVA controlling for the average percentage of time spent using the nonBasque language was conducted on the number of errors made for reading the lists, with Group (French, Spanish) as the between-subject factor and Lexicality (Words, Pseudowords) and Complexity (Complex, Simple) as the within-subject factors. No main effect or interaction was found (all $p \mathrm{~s}>0.05$ ).

\section{---- Insert Table 2. about here -----}

A similar ANCOVA was then conducted on the total time taken to read the whole list. First, there was a Lexicality effect $\left(F_{(1,43)}=9.66, p<0.005, \eta^{2}=0.18\right)$, illustrating that words were read more rapidly than pseudowords. Second, the effect of Lexicality was modulated by Complexity $\left(F_{(1,43)}=11.12, p<0.005, \eta^{2}=0.20\right)$. Bonferroni corrected post-hoc tests showed that whereas there was no lexical effect on simple items $(p>0.05)$, a significant lexical effect on reading speed emerged for complex items (complex words were read faster than complex pseudowords $p<0.001)$. Finally, the Lexicality by Complexity interaction was modulated by Group $\left(F_{(1,43)}=7.06, \mathrm{p}=0.01, \mathrm{MSE}=14.9\right.$, $\eta^{2}=0.14$, Figure 1). Bonferroni corrected post-hoc tests showed that Spanish-Basque bilinguals did not show any effect of complexity for words $(p>0.05)$ whereas the French-Basque bilinguals did $(p<0.001)$. The latter group read complex Basque words faster than simple Basque words. Regarding pseudowords, both groups showed a Complexity effect, reflecting faster reading times for simple compared to complex pseudowords $(p s<0.001)$. In addition, whereas no lexicality effect was found for simple items in either French-Basque or Spanish-Basque bilinguals ( $p s>0.05)$, significant lexicality effects emerged for both groups on the complex lists, illustrating faster reading times for words than pseudowords $(p s<0.001)$. . 
---- Insert Figure 1. about here -----

\subsection{Distribution of visual attention over letter strings: Visual 1-back task.}

According to signal detection theory (e.g., Green \& Swets, 1966), the accuracy scores obtained on our two-alternative forced-choice visual 1-back task ("YES", "NO") should reflect the children's (i) sensitivity (d-prime) in detecting the target letter, thus their ability to process all consonants at once (the quantity and quality of visual attention span resources), and (ii) their bias/criterion in making decisions about the presence of the target letter in the strings (their spatial bias in distributing their attention over the string of letters).

---- Insert Table 3. about here -----

First, an ANCOVA controlling for the average percentage of time spent using the non-Basque language was conducted on d-prime values (see Table 2), with Group (French, Spanish) as the between-subject factor, and Position $(1,2,3,4,5)$ as the within-subject factor. This analysis revealed only a significant Position effect $\left(F_{(4,168)}=\right.$ 2.97, $\left.p<0.05, \eta^{2}=0.07\right)$. Bonferroni corrected post-hoc tests showed that target detection at position 4 in the string was worse than at positions 1, 2 and 3 and that target detection at position 5 in the string was worse than at positions 1 and 3 (all $p s<0.005$ ).

---- Insert Figure 2. about here -----

Second, an ANCOVA controlling for the average percentage of time spent using French or Spanish as well as the averaged d-prime across the five positions was conducted on accuracy scores (see Table 3) with Group (French, Spanish) as the between-subject factor, and Position $(1,2,3,4,5)$ as the within-subject factor. This 
analysis allowed us to assess potential spatial bias in the distribution of visual attention, regardless of children's sensitivity in performing the task. This analysis revealed a significant Group by Position interaction, illustrating a bias of the Spanish-Basque bilinguals to distribute their visual attention towards the leftmost letters $\left(F_{(4,164)}=2.77\right.$, $p=0.03, \operatorname{MSE}=0.03, \eta^{2}=0.06$; see Figure 2). Bonferroni post-hoc tests showed that the Spanish-speaking group was more likely to detect the target at positions 1, 2, and 3 compared to the two rightmost positions (all $p s=<0.01$ ). French-Basque bilinguals were more likely to detect the target letter when it was presented at position 3 compared to position $4(p<0.005)$.

\subsection{Correlation analyses: Visual attention distribution and reading skills}

Since our hypothesis focused on the relationship between visual attention distribution and the presence of multi-letter graphemes, for each group, we computed composite individual reading z-scores, which corresponded to the average of the time and error $\mathrm{z}$ scores across the word and pseudoword lists for each condition - complex and simple (negative z-scores reflect higher performance). Partial correlations were run within each group between the composite "complex" and "simple" reading $\mathrm{z}$-scores and the accuracy scores obtained on the visual 1-back task controlling for the averaged d-prime values obtained across the five positions.

The analyses showed that in the French-Basque bilingual group, children who read the complex stimuli best (made the least errors and read more quickly) were those who had the best performance on the 1-back task, i.e. those who could identify a large number of consonants within the previously presented sequence and therefore could successfully distribute their visual attention resources over the whole consonant string 
$(r=-0.49, \mathrm{t}(21)=-2.60, \mathrm{p}=0.02)$. A similar (but non-significant) trend was observed for the simple items in this group $(r=-0.39, \mathrm{t}(21)=-1.94, \mathrm{p}=0.07)$. By contrast, performance in the visual 1-back task did not explain the reading performance of Spanish-Basque bilinguals either in the complex $(r=0.30, \mathrm{t}(23)=1.51, \mathrm{p}=0.15)$ or the simple $(r=0.19$, $\mathrm{t}(23)=0.93, \mathrm{p}=0.36)$ conditions. Scatterplots of the partial correlations are presented in Figure 3.

---- Insert Figure 3. about here -----

\section{Discussion}

Our rationale for the present study was based on the fact that bilinguals reading in one of their languages can recruit the cognitive resources that are specifically beneficial for reading in their other language. Accordingly, French-Basque bilinguals who had learned an inconsistent orthography in addition to Basque were previously shown to rely on a larger grain size when reading in Basque compared to SpanishBasque bilinguals who had learned to read in two consistent orthographies. For example, Lallier et al. (2016) found that French-Basque bilingual children exhibited a stronger reliance on whole words strategies (which was indexed by stronger lexical effects) than Spanish-Basque bilingual children when reading in their common consistent Basque orthography. In the same vein, Antzaka et al. (2018) showed that the VA span was wider for French-Basque than Spanish-Basque bilingual children. This wider attentional focus on letter strings was also linked to higher sensitivity to whole word orthographic processing in Basque measured in a serial letter naming task. 
The present study aimed to pinpoint the source of these grain-size accommodation processes in Basque bilinguals by isolating situations where grain size accommodation would be more strongly elicited. Our main hypothesis was that FrenchBasque bilinguals would be better at reading Basque words that included French multiletter grapheme clusters than Basque words which did not include these clusters. This hypothesis was based on evidence that complex graphemes boost lexical processing in inconsistent orthographies (Schmalz et al., 2016). By contrast, similar performance on both complex and simple Basque items was expected for Spanish-Basque bilinguals. Overall, our results are in line with the existence of cross-linguistic interactions that affect the reading grain size used by bilinguals in accordance with the "Grain Size Accomodation" hypothesis (Lallier \& Carreiras, 2018).

Here, we observed that only French-Basque bilinguals read complex words faster than simple words, suggesting that they were able to speed up lexical processing in Basque by utilizing a larger orthographic grain. Importantly, the Group by Complexity by Lexicality interaction shows that this complexity effect on word reading speed was not present in the Spanish-Basque bilinguals, suggesting that it probably came from the influence of French on Basque reading. The absence of such effects in the Spanish-Basque bilingual group is critical for the interpretation of our results. In fact, as items were presented in a fixed order on a sheet of paper, a list effect due to the presentation order of items could have explained the complexity effects observed on word reading speed. However, if the complexity effect on words was spurious and due to the constitution of the two lists, it should have been found across the two bilingual groups. The interaction with the group factor allows us to rule out this possibility. Overall, we identified an item-specific characteristic (i.e., the presence of complex multi-letter clusters) that, as we showed here, could act as a potential modulator of 
cross-linguistic transfer and grain size accommodation processes in bilingual reading. These results are in principle of theoretical interest since such clusters could explain sources of variability in the observation of cross-linguistic accommodation process across studies (Egan, Oppenheim, Saville, Moll, \& Jones, 2019).

\section{Positive complexity effects for word reading in French-Basque bilinguals: An (pre- ) orthographic origin?}

As mentioned above, we quantified the influence of the presence of French specific multi-letter clusters in Basque items on reading performance, and demonstrated that when Basque words included French multi-letter units, French-Basque bilinguals read the whole list faster than when these clusters were absent. Importantly, this effect was not observed in Spanish-Basque bilinguals.

Therefore, items that most effectively prompted French-Basque readers to rely on large orthographic chunks elicited a reading speed advantage over other types of items. Since large visual grain strategies are particularly beneficial for reading complex, unpredictable, and irregular graphemes in inconsistent orthographies (Lallier \& Carreiras, 2018), we assume that this effect stemmed from a cross-linguistic transfer from French to Basque reading. Importantly, one year earlier, we had found that the same French-Basque bilingual children exhibited larger lexical effects in Basque reading and broader VA span skills than Spanish-Basque bilinguals (see Lallier et al., 2016, which included 19 of the 25 French-Basque children tested in the present study). This suggests that the effect observed here, which we attribute to cross-linguistic transfer from French to Basque reading, is unlikely to be spurious but may instead be robust and persist across the years. 
In addition, we showed that French-Basque bilingual children exhibited French reading skills well within the range of age-matched French monolingual children on regular words, irregular words, and pseudowords. This is particularly important for the irregular word reading list, the condition that requires the use of large orthographic grains. Among these three lists, more than $30 \%$ of the items (23 out of the 60 ) included critical complex French clusters (e.g., rigueur, hausse, compteur). Out of a total of 478 inaccurately read items across the three reading lists, only $0.03 \%$ of these (14 errors) were errors made on complex clusters. This low proportion of errors on complex clusters suggests that the grapheme-to-phoneme mappings for these clusters had been mastered and interiorized by the French-Basque bilinguals tested in the present study. Overall, this data speaks in favor of the hypothesis that the French-Basque bilingual children relied on their relatively mature French orthographic skills and accessed the complex French graphemes when reading in Basque.

It is noteworthy that the presence of French complex clusters in Basque words could have worsened reading performance because of the phonological mismatch between French and Basque grapheme-to-phoneme conversions. This was not the case, at least for words. In fact, an extremely low number of errors (only four) made by the French-Basque bilinguals corresponded to the use of French grapheme-to-phoneme conversion rules. This strongly suggests that cross-linguistic transfer independent from phonological strategies affected the reading grain size when French speaking bilinguals read Basque lexical items. This is in line with the hypothesis that bilingual children over two years old have differentiated and separated phonological systems (Paradis, 2001), which also reduces the possibility that cross-language phonological interactions and mismatch could hinder the reading performance of French-Basque bilinguals. We propose that cross-linguistic transfer driven by the presence of French multi-letter 
clusters possibly affected the reading grain size at an (pre-) orthographic stage of processing: the fast activation of letter clusters at the orthographic level might have simply speeded phonological access and the process of phonological resolution. This hypothesis is corroborated by the results obtained on the visual 1-back task which was used to measure VA span skills that reflect pre-orthographic attentional processing that does not rely on phonological processes. First, we showed that the positional information of letters in strings in the visual 1-back task had a stronger effect on the distribution of visual attention in the Spanish-Basque than the French-Basque bilinguals: French-Basque bilinguals were less biased to spread their visual attention towards the left side of the letter strings and showed overall more homogeneous attentional distribution than Spanish-Basque bilinguals. Second, and as predicted, correlations indicated that French-Basque but not Spanish-Basque bilinguals relied on their VA span skills to read more efficiently in Basque, and more so when Basque items included a French multi-letter grapheme. This finding echoes those of Awadh et al. (2016) in monolinguals who demonstrated that VA span skills explained reading speed variance in French but not Spanish readers.

Overall, this set of results strongly suggests that visuo-orthographic strategies used to read in French were also applied to read Basque words. What about pseudowords?

\section{Negative complexity effects for pseudoword reading in both bilingual groups}

We found that both groups exhibited a significant complexity effect on pseudowords, illustrating a speed disadvantage when reading complex as compared to simple pseudowords (see Figure 1). This "negative" complexity effect on pseudowords 
was a priori expected for French-Basque bilinguals because of the phonological mismatch between the grapheme-to-phoneme conversion rules of their two languages. However, neither this complexity effect nor a stronger lexical effect for complex compared to simple items were expected in the Spanish speaking group who should have no knowledge of French grapheme-to-phoneme conversion rules. A first plausible explanation is that this complexity effect on pseudoword reading speed might have resulted from differences in the constitution of the two pseudoword lists. Indeed, we cannot rule out that this effect observed in both groups was due to the specific fixed order of presentation of the items in the lists. We acknowledge that future studies should investigate these effects with procedures that allow for timing individual items and the use of more sophisticated models. However, we believe that other explanations could shed light on these complexity effects found on pseudowords across groups. What could have led to a complexity disadvantage for pseudoword reading speed in the two bilingual groups and in particular in the Spanish speaking group?

In both complex lists, $57 \%$ of the items included vocalic digraphs (i.e., ai, ain, au, ei, eu, oi), whereas the remaining $43 \%$ included clusters composed of one vowel and one consonant (i.e., an, in, en, er, on, un). When read within words, vocalic digraphs form the perceptual center (or nucleus) of a unique syllable so that the word "AUrpegi" (face) would be read AUr-pe-gi. However, when encountered in pseudowords for which neither phonological nor orthographic lexical traces exist in memory, the probability that such vowel digraphs might be parsed as two vocalic syllables increases with the use of fine-grain grapheme-to-phoneme decoding strategies. For example, it becomes more likely that the pseudoword "paufegi" will be decoded as pA-U-fe-gi (instead of pAU-fegi) compared to the real and familiar word "jauregi" (jAU-re-gi, palace). If this hypothesis is correct, the total number of syllables read across the list of complex 
pseudowords was actually greater than the total number of syllables read across the list of simple pseudowords. This would explain why longer reading latencies were found for complex as compared to simple pseudowords in both groups. Still, the processes contributing to this effect might have been different between the two groups.

For the French-Basque bilingual group, we again propose that the crosslinguistic transfer from French-specific strategies to Basque reading which affected pseudoword performance might have been largely phonologically-independent and also relied on orthographic processes. Indeed, if a phonological mismatch between French and Basque grapheme-to-phoneme conversion rules had occurred, a larger negative complexity effect on pseudowords should have been observed for the French speaking compared to the Spanish speaking children. This was not the case. Several reasons allow us to argue that orthographic grain size made a significant contribution to the negative complexity effect on pseudowords observed in the French-Basque bilingual group. First, this effect was observed in absence of a higher number of errors made which tends to suggest that children were performing the task in a Basque (not French) grapheme-to-phoneme conversion mode. Second, the positive correlation found between VA span skills and complex item reading in the French speaking group strongly suggests that the children who were capable of broader visual capture of letter strings were those who read complex pseudowords best, possibly because of processing the vowel digraphs as a part of a unique syllabic unit (indeed, the positive correlations observed between VA span skills and the complex reading list in French-Basque bilinguals were significant not only for words but also for pseudowords). In contrast, Spanish speaking children showed a non-significant correlation between their VA span and their complex item reading skills. This result suggests that it is unlikely that the modulation of a visuo-orthographic grain contributed to complex item reading in the 
Spanish speaking group, favoring the hypothesis that these readers used decoding strategies that essentially relied on letter-phoneme mapping processes for both words and pseudowords.

\section{Conclusion}

Our results reveal that cross-linguistic similarities and transfer put some constraints on how bilinguals borrow reading-specific resources specific to one of their languages to read in their other language. The novel finding of this study is that grain size accommodation processes resulting from such cross-linguistic transfer in bilingual reading depend on the properties of the stimulus to be read. Here, we demonstrated that large grain processing strategies used in a consistent orthography like Basque are boosted when features of the second inconsistent language (French) are made available. We also added to our understanding of grain size accommodation processes by showing that the large grain size triggered by lexical properties may be favored when consolidated sub-lexical orthographic units, such as multi-letter graphemes, are made available. Future studies should determine whether these salient sub-lexical units speed lexical access by supporting more efficient orthographic parsing strategies that help break down lexical items into intermediate units.

\section{References}

Antzaka, A., Acha, J., Carreiras, M., \& Lallier, M. (2018). Author accepted manuscript: Does the visual attention span play a role in the morphological processing 
of orthographic stimuli? Quarterly Journal of Experimental Psychology, 1747021818806470.

Antzaka, A., Martin, C., Caffarra, S., Schlöffel, S., Carreiras, M., \& Lallier, M. (2018). The effect of orthographic depth on letter string processing: the case of visual attention span and rapid automatized naming. Reading and Writing, 31(3), 583-605

Awadh, F. H., Phénix, T., Antzaka, A., Lallier, M., Carreiras, M., \& Valdois, S. (2016). Cross-language modulation of visual attention span: an Arabic-Spanish-Basque comparison in skilled adult readers. Frontiers in Psychology, 7, 307.

Bosse, M. L., Tainturier, M. J., \& Valdois, S. (2007). Developmental dyslexia: The visual attention span deficit hypothesis. Cognition, 104(2), 198-230.

Bosse, M. L., \& Valdois, S. (2009). Influence of the visual attention span on child reading performance: a cross-sectional study. Journal of Research in Reading, 32(2), 230-253.

Buetler, K. A., de León Rodríguez, D., Laganaro, M., Müri, R., Spierer, L., \& Annoni, J. M. (2014). Language context modulates reading route: An electrical neuroimaging study. Frontiers in Human Neuroscience, $8,83$. doi:10.3389/fnhum.2014.00083

Burani, C. (2010). Word morphology enhances reading fluency in children with developmental dyslexia. Lingue e Linguaggio. 9, 177-198. doi:10.1418/33326

Burani, C. (2009). Reading fluency and morpho-lexical processing: developmental studies in Italian. Revista de Logopedia, Foniatría y Audiología, Vol. 29, No. 2, 97-103. de León Rodríguez, D., Buetler, K. A., Eggenberger, N., Laganaro, M., Nyffeler, T., Annoni, J. M., \& Müri, R. M. (2016). The impact of language opacity and proficiency 
on reading strategies in bilinguals: An eye movement study. Frontiers in Psychology, 7, 649. doi:10.3389/fpsyg.2016.00649

de León Rodriguez, D., Buetler, K. A., Eggenberger, N., Preisig, B. C., Schumacher, R., Laganaro, M.,\& Müri, R. M. (2015). The modulation of reading strategies by language opacity in early bilinguals: An eye movement study. Bilingualism: Language and Cognition, 19,567-577.

Duñabeitia, J. A., Casaponsa, A., Dimitropoulou, M., Martí, A., Larraza, S., \& Carreiras, M. (2017). BaSp: A Basque-Spanish database of translation equivalents. Manuscript in preparation.

Egan, C., Oppenheim, G. M., Saville, C., Moll, K., \& Jones, M. W. (2019). Bilinguals apply language-specific grain sizes during sentence reading. Cognition, 193, 104018.

Ellis, N. C., \& Hooper, A. M. (2001). Why learning to read is easier in Welsh than in English: Orthographic transparency effects evinced with frequency-matched tests. Applied Psycholinguistics, 22(4), 571-599.

García-Pentón, L., Fernández, A. P., Iturria-Medina, Y., Gillon-Dowens, M., \& Carreiras, M. (2014). Anatomical connectivity changes in the bilingual brain. Neuroimage, 84, 495-504.

Genesee, F., Geva, E., Dressler, C., \& Kamil, M. (2006). Synthesis: Cross-linguistic relationships. In D. August \& T. Shanahan (Eds.), Developing literacy in secondlanguage learners: Report of the National Literacy Panel on language-minority children and youth (pp. 153-174). Mahwah, NJ: Erlbaum. 
Goswami, U., Gombert, J. E., \& de Barrera, L. F. (1998). Children's orthographic representations and linguistic transparency: Nonsense word reading in English, French, and Spanish. Applied Psycholinguistics, 19(1), 19-52.

Goswami, U., Ziegler, J. C., Dalton, L., \& Schneider, W. (2001). Pseudohomophone effects and phonological recoding procedures in reading development in English and German. Journal of Memory and Language, 45(4), 648-664.

Green, D.M., \& Swets, J.A. (1966). Signal detection theory and psychophysics, Vol. 1. New York: Wiley.

Grosjean, F. (2010). Bilingualism, biculturalism, and deafness. International Journal of Bilingual Education and Bilingualism, 13(2), 133-145.

Hasenäcker, J., Schröter, P., \& Schroeder, S. (2017). Investigating developmental trajectories of morphemes as reading units in German. Journal of Experimental Psychology: Learning, Memory, and Cognition, 43(7), 1093.

Hull, R., \& Vaid, J. (2007). Bilingual language lateralization: A meta-analytic tale of two hemispheres. Neuropsychologia, 45(9), 1987-2008.

Jacquier-Roux, M., Valdois, S., \& Zorman, M. (2002). ODEDYS: un outil de dépistage des dyslexies Grenoble: Laboratoire cogni-sciences, IUFM de Grenoble.

Lallier, M., Acha, J., \& Carreiras, M. (2016). Cross-linguistic interactions influence reading development in bilinguals: a comparison between early balanced French-Basque and Spanish-Basque bilingual children. Developmental Science, 19(1), 76-89.

Lallier, M., \& Carreiras, M. (2018). Cross-linguistic transfer in bilinguals reading in two alphabetic orthographies: The grain size accommodation hypothesis. Psychonomic Bulletin \& Review, 25(1), 386-401. 
Lallier, M., Carreiras, M., Tainturier, M. J., Savill, N., \& Thierry, G. (2013). Orthographic transparency modulates the grain size of orthographic processing: behavioral and ERP evidence from bilingualism. Brain Research, 1505, 47-60.

Lallier, M., Thierry, G., Barr, P., Carreiras, M., \& Tainturier, M. J. (2018). Learning to read bilingually modulates the manifestations of dyslexia in adults. Scientific Studies of Reading, 22(4), 335-349.

Lee, M. D., \& Danileiko, I. (2014). Using cognitive models to combine probability estimates. Judgment and Decision Making, 9(3), 259.

Lobier, M., Zoubrinetzky, R., \& Valdois, S. (2012). The visual attention span deficit in dyslexia is visual and not verbal. Cortex, 48(6), 768-773.

Paradis, J. (2001). Do bilingual two-year-olds have separate phonological systems?. International journal of bilingualism, 5(1), 19-38.

Peereman, R., Sprenger-Charolles, L., \& Messaoud-Galusi, S. (2013). The contribution of morphology to the consistency of spelling-to-sound relations: A quantitative analysis based on French elementary school readers. L'Année Psychologique

Peyrin, C., Lallier, M., Demonet, J. F., Pernet, C., Baciu, M., Le Bas, J. F., \& Valdois, S. (2012). Neural dissociation of phonological and visual attention span disorders in developmental dyslexia: FMRI evidence from two case reports. Brain and Language, 120(3), 381-394.

Rau, A. K., Moll, K., Snowling, M. J., \& Landerl, K. (2015). Effects of orthographic consistency on eye movement behavior: German and English children and adults 
process the same words differently. Journal of Experimental Child Psychology, 130, 92105.

Saiegh-Haddad, E., \& Geva, E. (2010). Acquiring reading in two languages: An introduction to the special issue. Reading and Writing, 23, 263-267.

Schmalz, X., Beyersmann, E., Cavalli, E., \& Marinus, E. (2016). Unpredictability and complexity of print-to-speech correspondences increase reliance on lexical processes: More evidence for the orthographic depth hypothesis. Journal of Cognitive Psychology, 28(6), 658-672.

Schmalz, X., Marinus, E., Coltheart, M., \& Castles, A. (2015). Getting to the bottom of orthographic depth. Psychonomic Bulletin \& Review, 22(6), 1614-1629.

Seymour, P. H., Aro, M., Erskine, J. M., \& collaboration with COST Action A8 network. (2003). Foundation literacy acquisition in European orthographies. British Journal of Psychology, 94(2), 143-174.

Theeuwes, J. (2018). Visual selection: usually fast and automatic; seldom slow and volitional. Journal of Cognition. https://doi.org/10.5334/joc.13

Valdois, S., Bosse, M. L., Ans, B., Carbonnel, S., Zorman, M., David, D., \& Pellat, J. (2003). Phonological and visual processing deficits can dissociate in developmental dyslexia: Evidence from two case studies. Reading and Writing, 16(6), 541-572.

Wechsler, D. (2005). Wechsler Intelligence Scale for Children-Fourth EditionSpanish. San Antonio, TX: Harcourt Assessment.

Wimmer, H., \& Goswami, U. (1994). The influence of orthographic consistency on reading development: Word recognition in English and German children. Cognition, 51(1), 91-103. 
Ziegler, J. C., \& Goswami, U. (2005). Reading acquisition, developmental dyslexia, and skilled reading across languages: a psycholinguistic grain size theory. Psychological Bulletin, 131(1), 3.

Zoubrinetzky, R., Bielle, F., \& Valdois, S. (2014). New insights on developmental dyslexia subtypes: heterogeneity of mixed reading profiles. PLOS One, 9(6), e99337. 


\section{Tables}

Table 1. Descriptive statistics of the performance of the French-Basque bilinguals obtained on the three French reading lists.

\begin{tabular}{lcccccc}
\hline & \multicolumn{3}{c}{ Accuracy (/20) } & \multicolumn{3}{c}{ Time (sec) } \\
\hline & $\mathrm{M}(\mathrm{SD})$ & Range & $\mathrm{Z}$ score & $\mathrm{M}(\mathrm{SD})$ & Range & Z score \\
\hline Regular words & $16.3(2.5)$ & $7-20$ & -0.58 & $40.3(25.5)$ & $11-102$ & -0.40 \\
Irregular words & $9.6(4.5)$ & $4-20$ & -0.07 & $50.2(30.4)$ & $13-120$ & -0.33 \\
Pseudowords & $14.5(3.4)$ & $5-20$ & -0.35 & $47(27.6)$ & $15-130$ & -0.37 \\
\hline
\end{tabular}

Table 2. Descriptive statistics for the performance on the reading task.

\begin{tabular}{lcc}
\hline & $\begin{array}{c}\text { French-Basque bilinguals } \\
\text { Mean(SD) }\end{array}$ & $\begin{array}{c}\text { Spanish-Basque bilinguals } \\
\text { Mean(SD) }\end{array}$ \\
\hline Simple words & & \\
$\quad$ Num. of Errors & $2.04(1.92)$ & $2.96(2.80)$ \\
Total time (sec) & $73.75(30.92)$ & $60.52(26.64)$ \\
Complex words & & \\
$\quad$ Num. of Errors & $1.92(1.50)$ & $2.12(1.75)$ \\
$\quad$ Total time (sec) & $67.00(30.20)$ & $58.44(27.82)$ \\
\hline Simple pseudowords & & \\
$\quad$ Num. of Errors & $3.04(2.29)$ & $3.08(1.95)$ \\
$\quad$ Total time (sec) & $72.17(28.08)$ & $63.64(21.36)$ \\
Complex pseudowords & & \\
$\quad$ Num. of Errors & $3.21(2.71)$ & $2.12(2.08)$ \\
$\quad$ Total time (sec) & $79.50(30.31)$ & $68.00(22.38)$ \\
\hline
\end{tabular}

Table 3. Descriptive statistics for the performance on the visual 1-back task. 


\begin{tabular}{lcc}
\hline & $\begin{array}{c}\text { French-Basque bilinguals } \\
\text { Mean(SD) }\end{array}$ & $\begin{array}{c}\text { Spanish-Basque bilinguals } \\
\text { Mean(SD) }\end{array}$ \\
\hline Accuracy (\%) & & \\
Position 1 & $0.66(0.19)$ & $0.72(0.18)$ \\
Position 2 & $0.62(0.19)$ & $0.65(0.15)$ \\
Position 3 & $0.73(0.18)$ & $0.71(0.18)$ \\
Position 4 & $0.50(0.16)$ & $0.49(0.18)$ \\
Position 5 & $0.62(0.14)$ & $0.49(0.18)$ \\
Average & $0.63(0.10)$ & $0.61(0.10)$ \\
& & \\
Sensitivity (d-prime) & & $1.88(0.80)$ \\
Position 1 & $1.62(0.55)$ & $1.58(0.44)$ \\
Position 2 & $1.50(0.53)$ & $1.96(0.99)$ \\
Position 3 & $1.85(0.57)$ & $1.11(0.48)$ \\
Position 4 & $1.15(0.44)$ & $1.13(0.50)$ \\
Position 5 & $1.47(0.39)$ & $1.53(0.36)$ \\
Average & $1.52(0.31)$ & \\
\hline
\end{tabular}


Figures

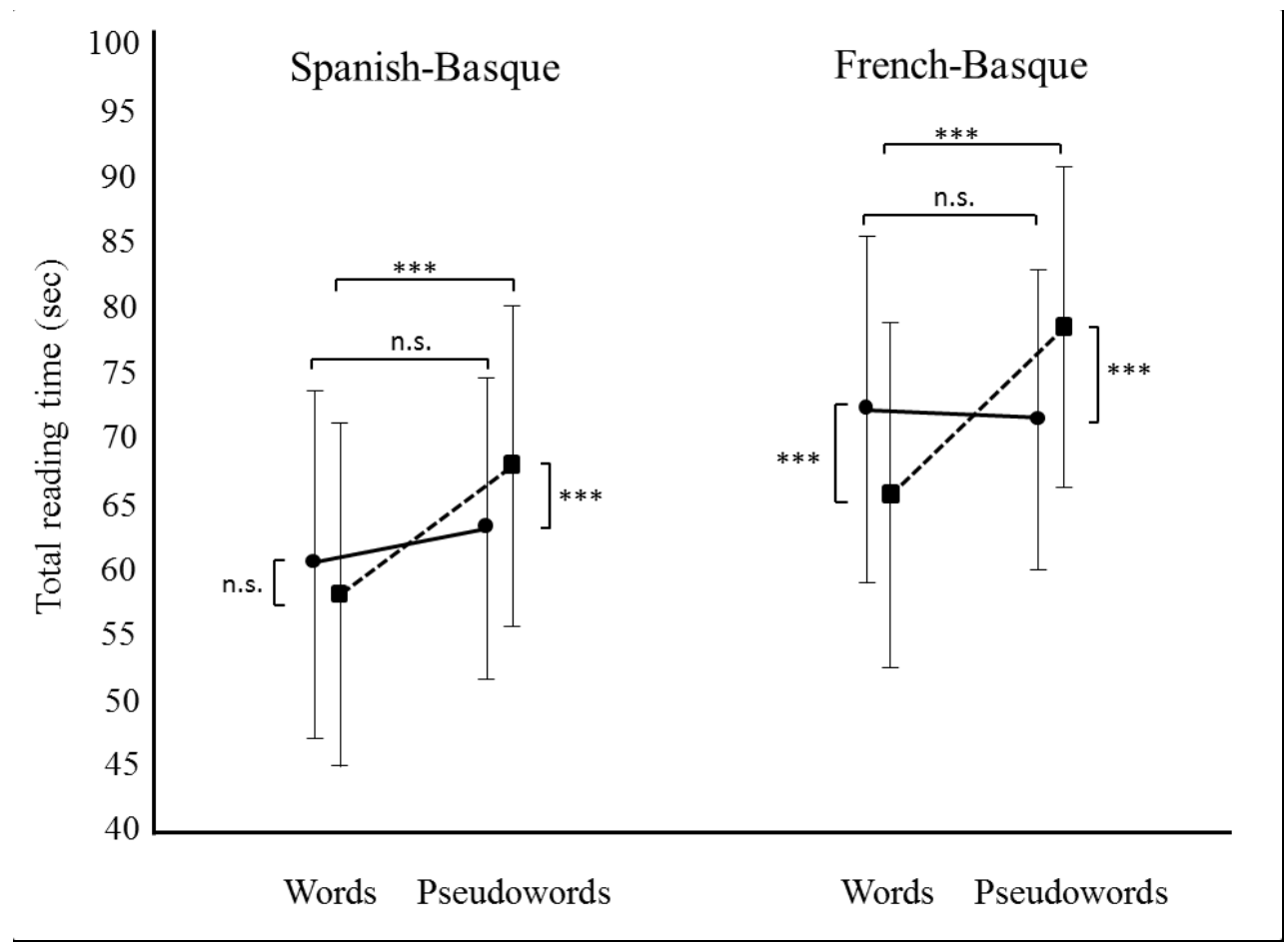

Figure 1. Total time taken to read the lists for the two groups of children. Plain lines represent the performance on simple items and dotted lines represent the performance on complex items. Vertical bars denote 0.95 confidence intervals. $* * *$ : $p<0.001$; n.s.: non-significant. Covariate means: Time spent using the other language $=32.6$. 


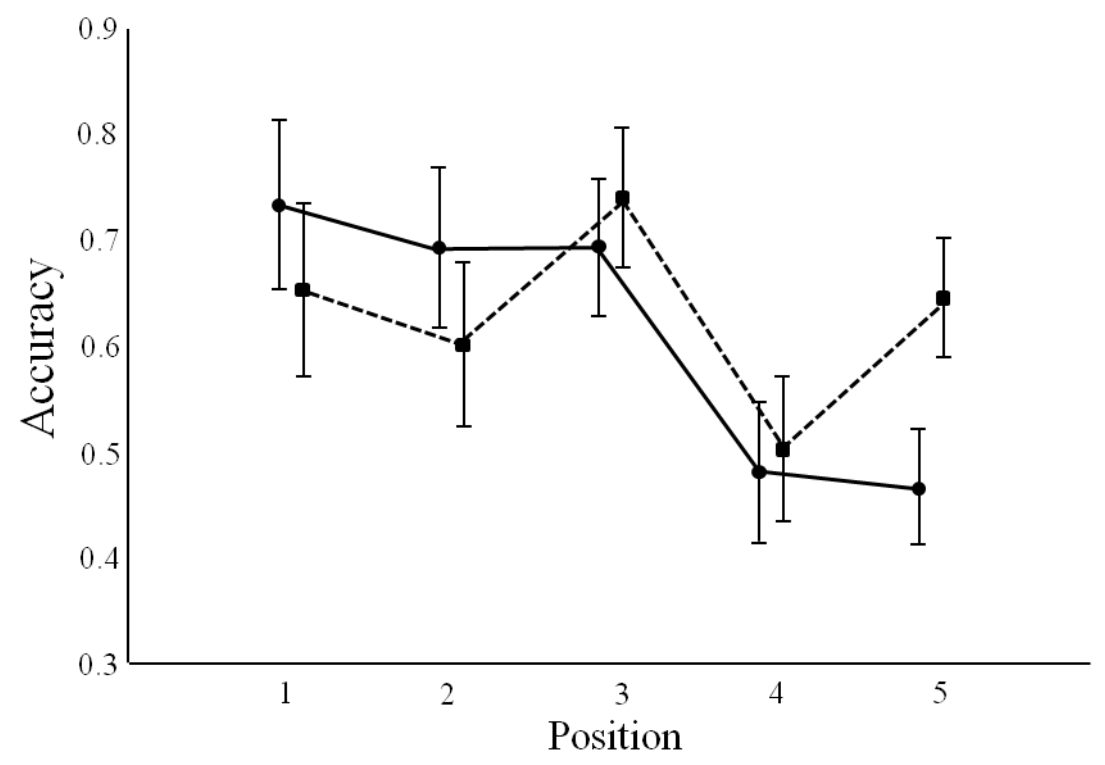

Figure 2. Performance on the visual 1-back task for the Spanish-Basque (plain lines) and the French-Basque (dotted lines) bilinguals. Vertical bars denote 0.95 confidence intervals. Covariate means: Time spent using the other language $=32.2$; Averaged $\mathrm{d}$ prime $=1.51$ 

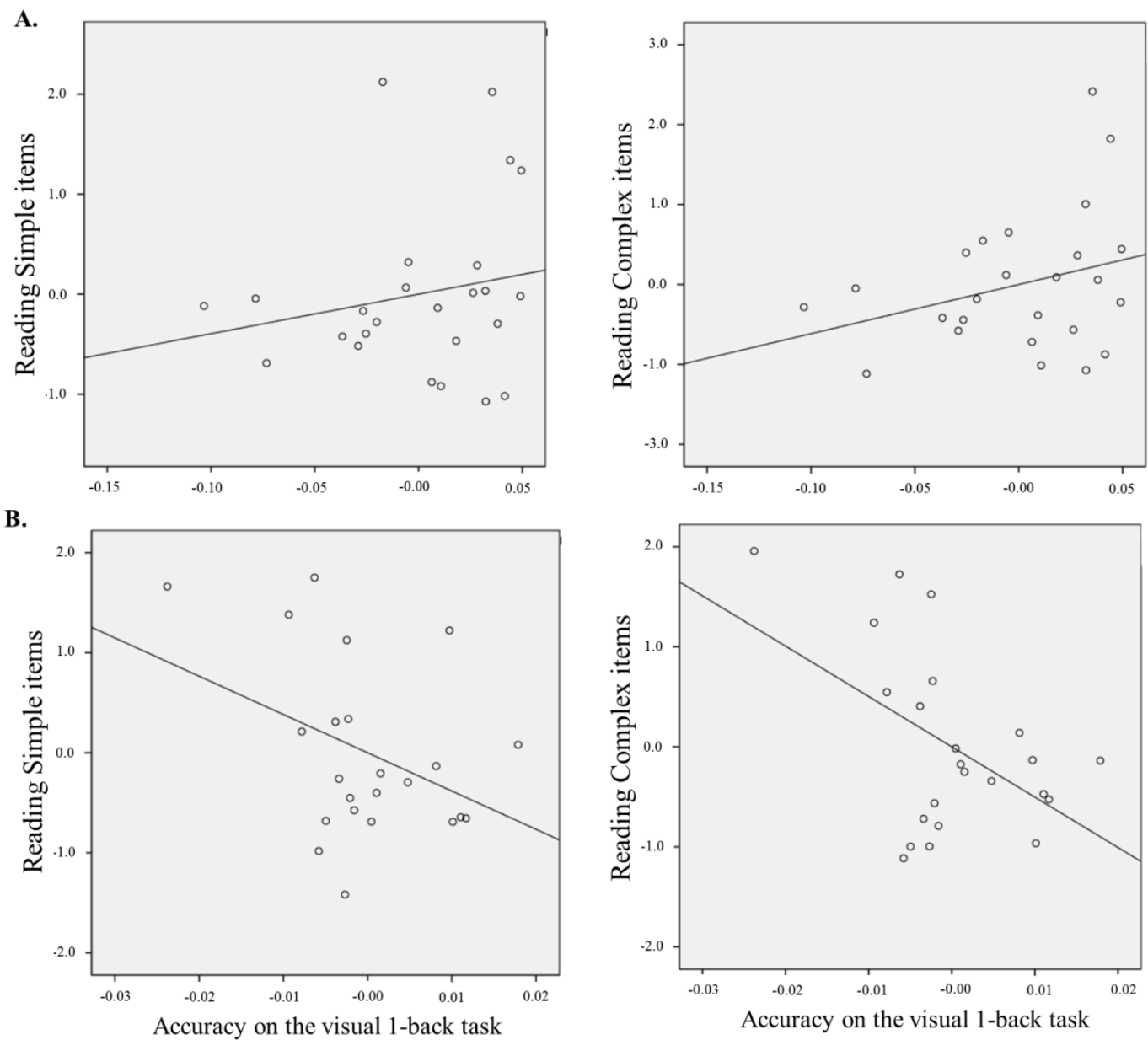

Figure 3. Scatter plots representing the partial correlations between reading and the breadth of attentional distribution on the visual 1-back task for the Spanish-Basque bilinguals (A.) and the French-Basque bilinguals (B). Unstandardized residuals are plotted. 


\section{Appendix}

List of items in the Basque reading task presented to the participants. Complex clusters are marked in bold.

\begin{tabular}{|c|c|c|c|}
\hline Words & & Pseudoword & \\
\hline Simple & Complex & Simple & Complex \\
\hline AFARI & AITONA & AKARI & ADAI \\
\hline ALDI & ALPER & ARKAR & AIGA \\
\hline ASTAKERIA & ANDERE & BARTO & AINGITA \\
\hline ASTINALDI & APAIZ & BASPI & AINTERI \\
\hline AZAL & ARTZAIN & BILEMO & AKAZOI \\
\hline AZERI & AUKERA & DEREZI & AMANTAULA \\
\hline AZKAR & AURPEGI & DIRO & ARKEN \\
\hline BALIO & AUSARDI & EGIZA & ARPAZOI \\
\hline BALIOGABE & AUZITEGI & EHIR & ASAITEN \\
\hline BASAKERIA & AUZO & ESKILARTO & ATAIN \\
\hline DARDARA & AUZOKIDE & HETIR & AUSKI \\
\hline DARDARATI & BAIMEN & HETO & EKONTO \\
\hline EHIZA & EKAIN & HEZAR & EMAIN \\
\hline ERDI & EULI & JOGO & ENDEI \\
\hline ESKU & EZTEI & KOPIRA & ENDORIO \\
\hline EZTARRI & GARAIPEN & KRITO & EUPI \\
\hline GAZTA & GIZEN & LARDARA & FANKA \\
\hline GELDIALDI & HANKA & LARGATI & FAURTARITZA \\
\hline GEREZI & HAURTZARO & LARRIABAL & GAIBASON \\
\hline GERRI & HAUTAGAI & LIRMOTAR & HINDAMUNDI \\
\hline GIHAR & HAUTESKUNDE & LIRRITARA & IKEN \\
\hline HERRI & INAUTERI & MARMOSA & INBURA \\
\hline HILERRI & IRIN & MARRERA & INTANDE \\
\hline HORMA & IRTEN & MARTOBI & IRPEN \\
\hline KAKALARDO & IZEN & NARTERA & ITIN \\
\hline LEKU & IZOKIN & NIRIKA & KAIKE \\
\hline NABARI & KIRTEN & OPOTAK & KINGARTI \\
\hline NOBELAGILE & KOIPE & ORTARBIL & LAIBRO \\
\hline ONARGARRI & LARUNBAT & PARLEKO & LENOI \\
\hline OSKOL & LEHOI & PARROZI & ODEN \\
\hline OSTIRAL & LUKAINKA & PEDOR & ONKOFIO \\
\hline PATRIKA & MAITASUN & PIFO & PAINKO \\
\hline SABEL & MAIZTASUN & SADOR & PAUFEGI \\
\hline SAGARDO & MENDE & SAZEL & PIZON \\
\hline SARBIDE & MENDI & TAZTA & SOTENDI \\
\hline TRESNA & OZEN & TIGA & TARRAITO \\
\hline ZALDI & SORGIN & TRIKO & ZAIMEN \\
\hline ZALDIZKO & ZELAI & ZALKI & ZAINTSUN \\
\hline ZIGOR & ZEZEN & ZENI & ZEMEN \\
\hline ZORROTADA & ZUZENDARI & ZIFOR & ZIKOIDA \\
\hline
\end{tabular}

